\title{
ANALISIS OPTIMALISASI KINERJA KARYAWAN MELALUI DIGITALISASI BISNIS DENGAN BUDAYA ORGANISASI SEBAGAI VARIABEL INTERVENING PADA PERUSAHAAN UMUM PERCETAKAN UANG REPUBLIK INDONESIA (PERUM PERURI) DIREKTORAT SDM DAN UMUM
}

\author{
Oleh : \\ Edi Suswardji \\ Fakultas Ekonomi - Universitas Singaperbangsa Karawang \\ E-mail: edisus.nugroho@fe.unsika.ac.id \\ Syaefudin Aziz \\ STMIK Pamitran Karawang \\ E-mail: azizkarawang19@gmail.com \\ Rysmi Wulandari
}

\begin{tabular}{l}
\hline Article Info \\
\hline Article History : \\
Received 23 July - 2020 \\
Accepted 20 August - 2020 \\
Available Online \\
07 Sept - 2020
\end{tabular}

Keyword :

Business Digitalization,

Organization Culture,

Employees Performance.

\begin{abstract}
The object of this research is the employees of Perum Peruri, Directorate HR and General. The research's method is descriptive verification, with data sources utilized are primary and secondary. From the population of 256 people, the sample was taken using a Probability sampling especially Proportionate Stratified Random Sampling obtained as many as 156 people. To measure the level of employees performance toward business digitalization with organizational culture as an intervening variable, processing data using path analysis with the SPSS 16 software application. The results showed that the implementation of business digitalization is assessed good by employees, organization culture is assessed good by employees and in general, optimization of employee performance is assessed good by employees. It is proved that business digitalization influence organizational culture and the level of influence is strong. It is proved that business digitalization influence employees performance and the level of influence is strong enough. It is proved that organization culture influence employees performance and the level of influence is strong.
\end{abstract}

\section{PENDAHULUAN}

Sumber daya manusia merupakan salah satu faktor yang sangat penting dalam suatu perusahaan disamping faktor lain seperti modal karena itu sumber daya manusia harus dikelola dengan baik untuk meningkatkan efektifitas dan efisiensi organisasi. SDM juga mempunyai peranan sentral dalam suatu organisasi. Tanpa SDM yang profesional, sasaran kerja tidak dapat dicapai walaupun apat kerjanya canggih. Oleh sebab itu, suatu organisasi harus memiliki strategi, kebijakan dan program kerja yang sesuai dengan kemampuan SDM untuk mengoperasikan alat kerja untuk mencapai sasaran kerja. (Prawironegoro, 2014).

Meningkatkan kualitas sumber daya manusia juga diharapkan dapat meningkatkan kinerja karyawan. Setiap perusahaan akan selalu berusaha untuk meningkatkan kinerja karyawannya, dengan harapan agar tujuan perusahaan dan individunya dapat tercapai. Menurut Mangkunegara (2012) dalam (Budiani, 2017) mengemukakan bahwa kinerja merupakan pencapaian hasil kerja karyawan 
berdasarkan kualitas maupun kuantitas sebagai prestasi kerja dalam periode waktu tertentu disesuaikan dengan tugas dan tanggung jawabnya. Setiap perusahaan atau instansi selalu mengharapkan karyawan yang berprestasi akan memberikan sumbangan yang optimal bagi perusahaan dan dapat meningkatkan kinerjanya.

Penelitian ini dilaksanakan di Perusahaan Umum Percetakan Republik Indonesia (Perum Peruri) Direktorat SDM dan Umum. Peruri merupakan satu-satunya Badan Usaha Milik Negara (BUMN) yang mendapat kepercayaan dari Pemerintah Republik Indonesia untuk melaksanakan pencetakan uang Rupiah, baik uang kertas maupun uang logam, sebagaimana diamanatkan oleh Undang Undang (UU) Nomor 7 Tahun 2011 tentang Mata Uang. Mengingat fungsi utamanya yang sangat penting bagi negara, Peruri ditetapkan sebagai Obyek Vital Nasional (Obvitnas) berdasarkan Keputusan Badan Intelijen Negara (BIN) Nomor R-459/VII/2004 tertanggal 31 Juli 2004 dan Obyek Vital Nasional Sektor Industri berdasarkan Surat Keputusan Menteri Perindustrian Nomor 466/M-IND/Kep/8/2014 tertanggal 2 September 2014.

Untuk melihat perkembangan pencapaian kinerja Perusahaan Umum Percetakan Republik Indonesia (Perum Peruri) saat ini, penulis telah mendapatkan data sekunder mengenai capaian kinerja karyawan Perusahaan Umum Percetakan Republik Indonesia (Perum Peruri) dalam kurun waktu beberapa tahun terakhir yang tersaji pada Gambar 1.1 berikut ini.

Gambar 1 Rekapitulasi Kinerja Perum Peruri

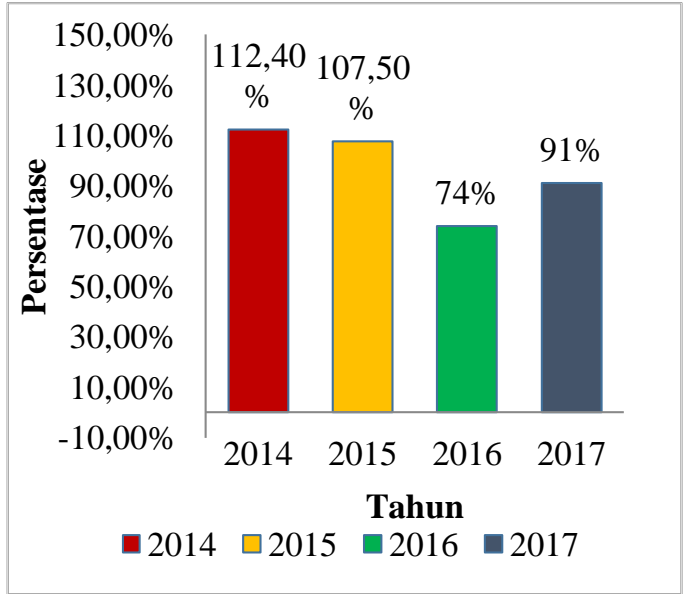

Sumber : Annual Report, 2015, 2016 dan 2017, dikelola tahun 2019.
Seperti yang tertera pada Tabel $1.1 \mathrm{di}$ atas dapat dilihat bahwa pencapaian kinerja Perum Peruri dalam beberapa tahun terakhir (Tahun 2014, 2015, 2016 dan 2017) mengalami fluktuasi. Hal ini terlihat masih terdapat kinerja yang tidak konsisten, kerena mengalami penurunan dan kenaikan yang berubah-ubah dari tahun ke tahun $(2014,2015,2016$ dan 2017) sehingga karyawan belum bisa dinilai dengan pasti dalam pencapaian kinerjanya.

Selain, data mengenai capaian kinerja pada Perum Peruri, penulis juga telah mendapatkan data sekunder mengenai Hasil Produksi Perum Peruri dalam kurun waktu beberapa tahun terakhir yang tersaji pada Tabel 1.1 berikut ini.

Tabel 1. Hasil Produksi Perum Peruri

\begin{tabular}{|c|c|c|c|c|}
\hline \multirow{2}{*}{$\begin{array}{c}\text { Jenis } \\
\text { Produksi }\end{array}$} & \multirow{2}{*}{$\begin{array}{l}\text { Satuan } \\
\text { (dalam } \\
\text { jutaan) }\end{array}$} & \multicolumn{3}{|c|}{ Tahun } \\
\hline & & 2015 & 2016 & 2017 \\
\hline \multicolumn{5}{|c|}{ Uang Dalam Negeri dan Luar Negeri; } \\
\hline \multirow{2}{*}{$\begin{array}{ll}\text { 1. } & \text { Uang } \\
\text { Kertas }\end{array}$} & \multirow{2}{*}{ Bilyet } & 9.29 & 6.16 & 11.0 \\
\hline & & 6 & 2 & 63 \\
\hline \multirow{2}{*}{$\begin{array}{ll}\text { 2. } & \text { Uang } \\
\text { Logam }\end{array}$} & \multirow{2}{*}{ Keping } & 1.58 & 2.11 & 2.29 \\
\hline & & 7 & 6 & 2 \\
\hline \multicolumn{5}{|c|}{ Non-Uang Dalam Negeri dan Luar Negeri; } \\
\hline $\begin{array}{ll}\text { 1. } & \text { Pita } \\
& \text { Cukai }\end{array}$ & Lembar & 180 & 169 & 170 \\
\hline $\begin{array}{ll}\text { 2. } & \text { Paspor } \\
\text { dan Buku }\end{array}$ & Buku & 5 & 4 & 4 \\
\hline $\begin{array}{l}\text { 3. Web and } \\
\text { Sheet }\end{array}$ & Rupiah & $\begin{array}{l}250 . \\
562\end{array}$ & $\begin{array}{l}266 . \\
323\end{array}$ & $\begin{array}{l}252 . \\
779\end{array}$ \\
\hline $\begin{array}{l}\text { 4. Logam } \\
\text { Non- } \\
\text { Uang } \\
\end{array}$ & Buah & 0,02 & 0,01 & 0,01 \\
\hline
\end{tabular}

Sumber : Annual Report, 2015, 2016 dan 2017, dikelola tahun 2019.

Seperti yang tertera pada Tabel 1.2 di atas dapat dilihat bahwa Hasil Produksi Perum Peruri dalam beberapa tahun terakhir (Tahun 2014, 2015, 2016 dan 2017) mengalami fluktuasi sama halnya dengan Pencapaian Kinerja Karyawan. Hal ini terlihat masih terdapat capaian target produksi yang belum konsisten, kerena mengalami penurunan dan kenaikan yang berubah-ubah sehingga karyawan belum bisa juga dinilai dengan pasti dalam pencapaian kinerjanya (Peruri, 2017). Hal ini tentu akan menjadi permasalahan yang serius di kemudian hari jika terus dibiarkan begitu saja tanpa adanya tindak lanjut dari perusahaan melihat kondisi yang ada pada perusahaan saat ini.

Nilai pada hasil kepuasan karyawan pada Perum Peruri pun masih belum optimal, karena berdasarkan laporan tahunan Perum Peruri 
(Peruri, 2017), nilai atas Kepuasan Karyawan hanya dapat memasuki kategori Moderat, yakni dengan nilai persentase kisaran 50\%. Masih ada indikator lain yang harus ditingkatkan guna tercapaianya sasaran kinerja yang diinginkan, karena karyawan merasa puas dengan pekerjaannya dan berdampak pada kinerjanya.

Guna mewujudkan cita-cita sesuai dengan visi, misi, tata nilai dan moto Perusahaan, diperlukan beberapa prasyarat adanya Budaya Organisasi pada Perum Peruri, yaitu dengan adanya Tata Nilai Peruri yang menjadi acuan para karyawan dalam bertindak di dalam organisasi, yang biasa disebut dengan INSTINK, yakni Integritas, Sekuriti, Teamwork, Inovasi dan Kualitas (Peruri, 2017). Nilai budaya organisasi tersebut diharapkan mampu meningkatkan kinerja organisasi dan mampu mencapai tujuan bersama.

Suatu perusahaan yang memiliki budaya yang kuat akan menghasilkan kinerja yang baik dalam jangka panjang. Budaya yang kuat artinya seluruh karyawan memiliki satu persepsi yang sama dalam mencapai tujuan perusahaan. Kesatuan persepsi didasarkan pada kesamaan nilai yang diyakini, norma yang dijunjung tinggi dan pola perilaku yang ditaati. (Prawironegoro, 2014).

Budaya organisasi merupakan ideologi bagi semua orang yang hidup dalam suatu organisasi atau perusahaan, yang harus diyakini dan dilaksanakan sebagai pedoman hidup. Budaya menentukan struktur organisasi, strategi dan kebijakan yang mana dalam rangka untuk penyempurnaan strategi perusahaan, dalam hal ini salah satunya dengan strategi pengembangan model bisnis digitalisasi bisnis dengan menggunakan teknologi yang baru dan mumpuni. (Prawironegoro, 2014).

\section{KAJIAN PUSTAKA PEGEMBANGAN HIPOTESIS}

DAN

Manajemen adalah suatu proses perencanaan, pengorganisasian, kepemimpinan dan pengendalian upaya dari anggota organisasi serta penggunaan semua sumber daya yang belum ada pada organisasi untuk mencapai tujuan organisasi yang ditetapkan sebelumnya.

Sumber Daya Manusia suatu cara mencapai tujuan dengan cara menggerakan organisasi melalui perencanaan pengorganisasian, pelaksanaan dan pengendalian yang baik, sehingga menjadi sumber daya manusia yang terdidik, terampil, cakap, berdisiplin, tekun kreatif, idealis, mau bekerja keras, kuat fisik dan mental serta setia kepada citacita dan tujuan organisasi akan berpengaruh positif terhadap keberhasilan dan kemajuan oganisasi.

Digitalisasi bisnis merupakan proses mengolah dan menganalisis segala aktivitas bisnis dalam rangka untuk mengubah tatanan bisnis sebuah organiasi untuk dapat berjalan dengan proses digital demi terciptanya tujuan yang lebih efektif dan efisien.

Budaya organisasi adalah cara kita melakukan sesuatu seperti pola nilai, norma, keyakinan, sikap dan asumsi yang mungkin tidak diungkapkan, tetapi akan membentuk cara orang berpikir dan berperilaku dalam melakukan sesuatu. Nilai mengacu kepada apa yang diyakini merupakan hal penting mengenai cara orang dan organisasi berperilaku. Norma adalah peraturan tidak tertulis mengenai perilaku. Maka budaya organisasi adalah sebuah keyakinan, sikap dan nilai yang umumnya dimiliki, yang timbul dalam organisasi yang membedakan organisasi tersebut dengan organisasi yang lain.

Kinerja hasil kerja karyawan baik kualitas maupun kuantitas yang dicapai oleh karyawan dalam periode tertentu sesuai dengan tanggung jawab yang diberikan. Tentunya hasil kerja yang dihasilkan oleh karyawan diharapkan mampu memenuhi keinginan perusahaan dan berjalan seimbang sesuai dengan tujuan perusahaan. Agar terciptanya kinerja yang terus meningkat tanpa adanya penurunan.

\section{METODE PENELITIAN}

Menurut Sugiyono (Sugiyono, 2018), metode penelitian pada dasarnya merupakan cara ilmiah untuk mendapatkan data dengan tujuan dan kegunaan tertentu. Kegiatan penelitian itu didasarkan pada ciri-ciri keilmuan, yaitu rasional, empiris dan sistematis. Studi ini membantu peneliti menjelaskan subjek yang akan diteliti. Pada penelitian ini menggunakan metode penelitian deskriptif dan verifikatif.

Penelitian deskriptif adalah suatu metode dalam penelitian suatu kelompok manusia atau objek, suatu kondisi, suatu sistem pemikiran ataupun suatu kelas peristiwa pada masa sekarang untuk mengetahui nilai variabel mandiri, bak satu variabel atau lebih (independen) tanpa membuat perbandingan, atau menghubungkan dengan variabel lain. 
Tujuan penelitian deskriptif ini adalah untuk membuat deskripsi, gambaran atau lukisan secara sistematis, aktual dan akurat mengenai fakta-fakta serta hubungan antara fenomena yang diselidiki.

Penelitian verifikatif menurut (Sugiyono, 2018) adalah metode penelitian kuantitatif yang dapat diartikan sebagai metode penelitian yang digunakan untuk meneliti sampel atau populasi tertentu, dan analisis data berupa statistik yang bertujuan untuk menguji suatu teori atau hasil penelitian sebelumnya, sehingga diperoleh hasil yang memperkuat atau menggugurkan teori atau hasil penelitian sebelumnya.

Penelitian deskriptif meliputi analisis rentang sekala, sedangkan metode verifikatif digunakan untuk mengetahui hubungan antarvariabel melalui pengujian hipotesis meliputi pengujian pengaruh Digitalisasi Bisnis $(X)$ terhadap Budaya Organisasi $(Y)$, pengaruh Digitalisasi Bisnis $(X)$ terhadap Kinerja Karyawan $(Z)$ dan pengaruh Budaya Organisasi $(Y)$ terhadap Kinerja Karyawan $(Z)$ dengan menggunakan uji t. Secara deskriptif bertujuan untuk memperoleh gambaran mengenai variabel Digitalisasi Bisnis sebagai variabel bebasnya, Budaya Organisasi sebagai variabel intervening dan Kinerja Karyawan sebagai variabel terikat. Sedangkan secara verifikatif bertujuan untuk menguji hipotesisi dengan perhitungan statistik.

Variabel mediasi (atau variabel intervening) adalah variabel yang muncul antara waktu variabel independen mulai beroperasi untuk memengaruhi variabel dependen dan waktu dampaknya dirasakan di sana. Dengan demikian ada kualitas temporal atau dimensi waktu untuk variabel mediasi. Dengan kata lain, menjalankan variabel mediasi membantu Anda membuat model suatu proses. Variabel mediasi muncul sebagai fungsi dari variabel independen yang beroperasi dalam situasi apa pun, dan membantu untuk membuat konsep dan menjelaskan pengaruh variabel independen terhadap variabel dependen. Contoh berikut menggambarkan hal ini. (Sekaran \& Bougie, 2016).

Hipotesis penelitian merupakan dugaan awal atau kesimpulan sementara pengaruh variabel independen terhadap variabel dependen sebelum dilakukan penelitian dan harus dibuktikan melalalui penelitian. Berdasarkan landasan teori dan kerangka berpikir di atas, maka Hipotesis yang diajukan dalam penelitian ini adalah :
$H_{1}$ : Terdapat pengaruh Digitalisasi Bisnis $(X)$ terhadap Budaya Organisasi $(Y)$ pada Perusahaan Umum Percetakan Uang Republik Indonesia (Perum Peruri) Direktorat SDM dan Umum.

$H_{2}$ : Terdapat pengaruh Digitalisasi Bisnis $(X)$ terhadap Kinerja Karyawan (Z) pada Perusahaan Umum Percetakan Uang Republik Indonesia (Perum Peruri) Direktorat SDM dan Umum.

$H_{3}$ : Terdapat pengaruh Budaya Organisasi $(Y)$ terhadap Kinerja Karyawan $(Z)$ pada Perusahaan Umum Percetakan Uang Republik Indonesia (Perum Peruri) Direktorat SDM dan Umum.

\section{HASIL DAN PEMBAHASAN}

Penelitian ini meneliti 3 variabel di Perusahaan Umum Percetakan Uang Republik Indonesia (Perum Peruri) Direktorat SDM dan Umum, yakni Analisis Optimalisasi Kinerja Karyawan melalui Digitalisasi Bisnis dengan Budaya Organisasi sebagai Variabel Intervening. Adapun rincian setiap variabel adalah sebagai berikut :

a. Digitalisasi Bisnis di Perusahaan Umum Percetakan Uang Republik Indonesia (Perum Peruri) Direktorat SDM dan Umum

Berdasarkan hasil penelitian diperoleh bahwa digitalisasi bisnis di Perusahaan Umum Percetakan Uang Republik Indonesia (Perum Peruri) Direktorat SDM dan Umum terbagi atas dua kelompok yaitu kelompok kriteria sangat setuju dan kriteria setuju. Kelompok kriteria sangat setuju terdiri dari lima indikator yaitu penciptaan nilai, dorongan, komitmen pada transformasi, aktivitas dan paduan sdm dengan sumber digital. Sedangkan kelompok kriteria setuju terdiri dari sepuluh indikator yaitu pola pikir digital, penemuan kembali, digital skill, know-how, and talent, design model business, potensi, penggunaan data, fundamental TI, proses data, modul panduan, dan pengetahuan.

b. Budaya Organisasi di Perusahaan Umum Percetakan Uang Republik Indonesia (Perum Peruri) Direktorat SDM dan Umum

Berdasarkan hasil penelitian diperoleh bahwa budaya organisasi di Perusahaan Umum Percetakan Uang Republik Indonesia (Perum Peruri) Direktorat SDM dan Umum terbagi atas tiga kelompok yaitu 
kelompok kriteria sangat setuju, kriteria setuju dan kriteria kurang setuju. Kelompok kriteria sangat setuju terdiri dari lima indikator yaitu tantangan, aturan, manfaat, tujuan tim dan keharmonisan. Sedangkan kelompok kriteria setuju terdiri dari delapan indikator, yaitu pembaruan, perubahan, keteraturan, kejelasan, kesesuaian dengan standar, stabilitas hasil, stabilitas perilaku dan stabilitas tujuan. Sedangkan untuk kelompok kriteria kurang setuju terdiri dari satu indikator yaitu perbedaan hasil.

c. Kinerja Karyawan di di Perusahaan Umum Percetakan Uang Republik Indonesia (Perum Peruri) Direktorat SDM dan Umum

Berdasarkan hasil penelitian diperoleh bahwa kinerja karyawan di Perusahaan Umum Percetakan Uang Republik Indonesia (Perum Peruri) Direktorat SDM dan Umum terbagi atas tiga kelompok yaitu kelompok kriteria sangat setuju, kriteria setuju dan kriteria kurang setuju. Kelompok kriteria sangat setuju terdiri dari satu indikator yaitu hasil kerja sesuai dengan standar, kelompok kriteria setuju terdiri dari tujuh indikator yaitu jumlah hasil sesuai dengan standar, jumlah hasil melebihi rekan kerja, waktu penyelesaian tugas, tingkat pengetahuan pedoman kerja, tingkat keterampilan, keterlambatan dan absensi. Sedangkan untuk kelompok kriteria kurang setuju terdiri dari satu indikator yaitu tingkat kesalahan.

Adapun pembahasan dari metode verifikatif dalam penelitian ini dapat diuraikan sebagai berikut :

\section{a. Pengaruh Digitalisasi Bisnis terhadap Budaya Organisasi}

Pengaruh variabel digitalisasi bisnis terhadap budaya organisasi memiliki nilai sebesar 50,3\%. Hal ini menunjukkan bahwa digitalisasi bisnis memiliki pengaruh positif terhadap budaya organisasi. Hal ini didukung oleh teori Prawironegoro (2014) yang menyatakan bahwa pembaruan (digitalisasi) konsep pada perusahaan akan membawa perubahan pula pada pola perilaku karyawan (budaya organisasi). Ketika organisasi telah melakukan pembaruan atau digitalisasi pada bisnisnya tentunya akan membawa perubahan pada kinerja yang lebih baik, seperti yang telah diungkapkan oleh Dase (2018) yang menyatakan bahwa optimalisasi sumber daya dapat dicapai dengan menggunakan teknologi untuk meningkatkan kinerja operasi dalam rangka menunjang kegiatan bisnis perusahaan.

b. Pengaruh Digitalisasi Bisnis terhadap Kinerja Karyawan

Pengaruh variabel digitalisasi bisnis terhadap kinerja karyawan memiliki nilai sebesar 16,9\%. Hal ini menunjukkan bahwa digitalisasi bisnis memiliki pengaruh positif terhadap kinerja karyawan. Hal ini juga mendukung penelitian yang dilakukan oleh Vinit Parida (2019) yang menyatakan bahwa kemunculan teknologi dan aplikasi digital seperti Internet of Things (IoT), Industri 4.0, kecerdasan buatan, otomatisasi, pemantauan jarak jauh, perawatan prediktif, kontrak pintar, data besar, cloud, analitik, dan produk-produk terhubung pintar menawarkan banyak peluang pengembangan bisnis. Yang dalam hal ini dapat diartikan bahwa perubahan yang ada yang dilandaskan dari digitalisasi dapat merujuk pada pembaruan kinerja pada suatu organisasi.

c. Pengaruh Budaya Organisasi terhadap Kinerja Karyawan

Pengaruh variabel budaya organisasi terhadap kinerja karyawan memiliki nilai sebesar 50,2\%. Hal ini menunjukkan bahwa budaya organisasi memiliki pengaruh positif terhadap kinerja karyawan. Hal ini sejalan dengan teori dari Maximini (2015) yang menyatakan bahwa hal utama dari budaya organisasi terletak pada ketertarikan seseorang yang ada pada pikiran masingmasing orang. Maka, perusahaan harus mampu menganalisis setiap karakter karyawannya guna menentukan arah untuk kemajuan perusahaan, dalam hal ini dalam lingkup kinerja karyawan.

\section{KESIMPULAN}

Berdasarkan hasil penelitian dan pembahasan, maka dapat ditasik kesimpulan sebagai berikut ini :

a. digitalisasi bisnis yang ada pada Perusahaan Umum Percetakan Uang Republik Indonesia (Perum Peruri) Direktorat SDM dan Umum masuk dalam kategori baik, hal ini dibuktikan dari total skor sebesar 9441 dengan rata-rata skor 629,4 yang berada pada rentang skala antara 531,1 - 656,1 dengan kriteria setuju. Akan tetapi, terdapat 
indikator yang memiliki nilai terendah yaitu indikator modul panduan dengan skor sebesar 539 dan indikator yang memiliki nilai tertinggi yaitu indikator komitmen pada transformasi dengan skor 682 .

b. Budaya organisasi di Perusahaan Umum Percetakan Uang Republik Indonesia (Perum Peruri) Direktorat SDM dan Umum masuk dalam kategori baik, hal ini dibuktikan dari total skor sebesar 8869 dengan rata-rata skor 633,5 yang berada pada rentang skala antara $531,1-656,1$ dengan kriteria setuju. Akan tetapi, terdapat indikator yang memiliki nilai terendah yaitu indikator perbedaan hasil dengan skor sebesar 517 dan indikator yang memiliki nilai tertinggi yaitu indikator keharmonisan dengan skor 685.

c. Kinerja karyawan di Perusahaan Umum Percetakan Uang Republik Indonesia (Perum Peruri) Direktorat SDM dan Umum masuk dalam kategori optimal, hal ini dibuktikan dari total skor sebesar 5456 dengan rata-rata skor 606,2 yang berada pada rentang skala antara $531,1-656,1$ dengan kriteria setuju. Akan tetapi, terdapat indikator yang memiliki nilai terendah yaitu indikator tingkat kesalahan dengan skor sebesar 484 dan indikator yang memiliki nilai tertinggi yaitu indikator hasil kerja sesuai dengan standar dengan skor 665 .

d. Pengaruh digitalisasi bisnis terhadap budaya organisasi di Perusahaan Umum Percetakan Uang Republik Indonesia (Perum Peruri) Direktorat SDM dan Umum memiliki nilai sebesar 50,3\%. Hal ini menunjukkan bahwa digitalisasi bisnis memiliki pengaruh positif dan signifikan terhadap budaya organisasi.

e. Pengaruh digitalisasi bisnis terhadap kinerja karyawan di Perusahaan Umum Percetakan Uang Republik Indonesia (Perum Peruri) Direktorat SDM dan Umum memiliki nilai sebesar 16,9. Hal ini menunjukkan bahwa digitalisasi bisnis memiliki pengaruh positif dan signifikan terhadap kinerja karyawan.

f. Pengaruh budaya organisasi terhadap kinerja karyawan di Perusahaan Umum Percetakan Uang Republik Indonesia (Perum Peruri) Direktorat SDM dan Umum memiliki nilai sebesar $50,2 \%$ terhadap kinerja karyawan. Hal ini menunjukkan bahwa budaya organisasi memiliki pengaruh positif dan signifikan terhadap kinerja karyawan.

\section{REFERENSI}

Budiani, R. 2017. "Pengaruh Disiplin Kerja dan Motivasi Terhadap Kinerja Karyawan”. PT. Inti Bumi Perkasa. Repository Universitas Pasundan.

Mangkunegara, A. P. 2011. "Manajemen Sumber Daya Manusia Perusahaan". Bandung: PT. Remaja Rosdakarya.

Maximini. 2015. "Organization Culture Models". International Journal of Springer International Publishing Switzerland. DOI 10.1007/978-3-319-11827-7_2.

Prawironegoro, D. 2014. "Manajemen Strategis”. Jakarta: Mitra Wacana Media.

Sekaran, U., \& Bougie, R. 2016. "Research Methods for Business". Chichester, West Sussex, United Kingdom: John Wiley \& Sons Publisher.

Sugiyono, P. D. 2018. "Metode Penelitian Kuantitatif, Kualitatif dan R\&D". Bandung: Alfabeta.

Vinit Parida, d. 2019. "Reviewing Literature on Digitalization, Business Model Innovation, and Sustainable Industry: Past Achievements and Future Promises". International Journals of Sustainability.

http://www.peruri.co.id diakses pada 14 Maret 2019 pada pukul 19.00

https://www.ilo.org/ diakses pada 14 Maret 2019 pada pukul 20.25 https://inet.detik.com/telecommunication/3 400631/digitalisasi adalah-kunci diakses pada 14 Maret 2019 pada pukul 20.20

https://www.marketeers.com diakses pada 14 Maret 2019 pada pukul 19.20 